\title{
The Effect of Media on Crime: With Emphasis on Pathological Aspects of TV and Internet
}

\author{
Ph.D Reza Ali Mohseni \\ Associate Professor of sociology. Faculty member of Islamic Azad University \\ Central Tehran Branch (corresponding author); Mohseninet@yahoo.com
}

\author{
Ali Latifinia \\ MSc of International relations in Islamic Azad University, Science and Research Branch Qom \\ Saeideh Sadeghi Afjeh
}

MSc of Public management in transformation tendency from Islamic Azad University Naragh

\section{Doi:10.5901/mjss.2016.v7n4s2p154}

\section{Abstract}

\begin{abstract}
Mass media are accounted as the significant and pervasive part of the society's system. Nowadays the vast presence of mass media in orienting the public opinions of the world is from undeniable realities that has influenced on contemporary world from numerous aspects. This meaning has proceeded to an extent that current era was called "media era". New society without mass media is almost unimaginable and living in the third millennium without media seems impossible. Media are always reminded as the effective factor on different social, political, economic and cultural domains. Since intellectual nourishment of most of the society's people is done through media, the media can be effective on persons, attitude to the environment. Media have positive and negative functions for the members of society and family especially children. Child and media have mutual, constant and effective relation. Both children are from the most serious interested and applicant of new media especially TV, computer games and internet and media have severe tendency to invest for producing the children and adolescents programs for attraction of new generations and imposition of inspirations of negative messages of media. From consequences of new generation media, pornography, violence and crime of media can be referred. This article studies the social pathology of media. The main emphasis of this writing is on analysis of social-mental threats of TV and internet and their effects on children and women from pathologic view.
\end{abstract}

Keywords: Media, pathology, TV, internet, media crimes

\section{Introduction}

Nowadays, the vast presence of mass media in orienting the public opinions of the world is from the undeniable realities that has influenced on contemporary world from numerous aspects. This meaning has proceeded to an extent that current era was called "media era". Media in recent years beside the informant and educational role, have undertaken another mission and that is the investigative and inspective role. According to this, media with their revelation break the silence of governmental and formal authorities and compensate it and through informing the public opinion press on the governments to indicate proportional relations from themselves in the cases of severe violation of norms and perpetration of severe crimes and prevent from «tender» and ignorable methods (Delmas Marti, 2002: 5-304).

Mass media are accounted as the most important, attractive and at the same time critical aspect of modern society. In the meantime, the role of visual media especially TV, satellite and internet is more prominent than other media.

Sociologists believe that technology is an important factor in social changes. Technology doesn't do anything automatically, but without access to the public media, social change is impossible. The person's communication has grown in the face to face form gradually, through public media technology, it has been converted to a public communication.

Advent and growth of public media in deep form have caused to change the method of transmitting the culture from a generation to another generation. In addition to this, due to this issue that nowadays public media can present much information to a great number of addressees simultaneously, their role for quick transmission of culture has significant importance. Each one of the media networks (TV, radio, newspaper, magazine, book, cinema and etc) transmits cultural 
messages in the form or content of news or entertainment (Azdanlou, 2005: 325).

This issue that public media have role in the primary sociability of children and long-term sociability of adults is an undeniable issue. A part of sociability is related to the media that practically overlaps with other social effects and different methods of sociability inside the family (nossnideh, 2008).

Media have wonderful effect on public opinions and beliefs. In fact they form the public opinions and on the other hand reflect them. Media influence on our understanding from around world. The worlds color and what is in it are as a function of our understanding from the world and media have wonderful effect on this worldview. Media have an important role in protecting and strengthening the public participation and consequently public safety, increasing the ability of society's selection, increasing the people, competition and dynamism, internalizing and institutionalizing the value system and introducer beliefs and the settlement affairs of contradictions and cultural-social diversities.

Mass media are as the illustrator of the society's culture for audiences and therefore, they play an important role in the sociability process. Here, the attention is more on the transmission method than the media contents. Marshal Mcluhan (1967) believes the media are messages. From his view, the media kind independent from what says, forms and controls the human's communication and acts.

Public media (TV, cinema, the publications) don't play new roles in relation with satisfying today's needs. According to the «scarcity hypothesis», Ronald Inglehart that believes the person's priorities are as the reflection of his socialeconomic environment, the person considers the most priorities for those things that supply of them is relatively little (Inglehart, 1994: 75). Media and especially TV have significant effect on formation of beliefs, attitudes and behavior.

The researches indicate that most of TV observers are the children lower than 15 years old and after them housekeeper women and then the youth higher than 15 years old (Newman, 2008). Social sociologists and psychologists have studied different aspects of the media content, with regard to the cognitive effect of TV, it can be said that TV has influenced on behavioral models severely and in relation with the mental-moral health of person and his compatibility with society, it has intensified the affairs like aggression, emotional abnormalities, tool and exertion of violence and like them.

At current era, mass media in terms of technology have progressed abundantly. But their content hasn't been evolved along with development of technology from humane aspect. In fact, it can be said that there is large gap between technological progress of media and semantic progress and evolution of the media content. This procedure can be known as a kind of cultural lag. Namely, the society culturally hasn't produced the norms, values and necessary rules for using of technological tool and the cultural technology progress is dominant on the progress of technology culture.

Violence and pornography are two categories that have overshadowed on today media (multimedia systems) severely. Nowadays most of children and adolescents daily observe violent and profligate scenes from TV and other mass media.

Referring to a part of the research data expresses the realities more:

Criminal news and incidents have allocated a main part of contents of all mass media to themselves. Accomplished studies indicate that criminal news include at least 4 percent, at most 28 percent and averagely 7 percent of the newspapers issues. This ratio about visual-audio media has allocated different percent between 10 to 13 according to different time periods and geographical environments to itself (Sherizen, 1978: 208).

- In America, students before reaching to 18 years old have seen and heard 200000 times violent act and 140000 times sexual message.

- Each American child that becomes 18 years old has seen 18000 scenes of murder simulation in TV (Hamarberg, 2001: 27).

- Every five minutes, each American child due to the perpetration of a violent crime is arrested and every three hours, violence and of course with firearms kills a child (Vartella \& et al, 2001: 79).

Media with reflection of the news related to the criminal phenomena impose special attitude on people and organize the manner of their judgement about crime and penal justice. These communicative tools simply can make a very important subject from a low important issue and they can sensitize the public opinions to a special phenomenon or vice versa they can make neutral and low important news from an important incident (Farjiha, 2006).

Nevertheless, it can be expressed that study about mass media functions, their consequences and achievements and effects on mental-social health of the society's people (publically) and family (specifically) has abundant importance.

\section{Concepts Definition}

\subsection{Media}

Media are communicative devices and embrace many carriers (Kasno, 2002: 3). Kotler calls media as non-personal 
communicative devices that cause the message and opinions news of sender to reach to the receiver and he knows them including printing devices (newspaper, magazine and direct post), audio-visual media (radio and TV), demonstrative devices like inter-way panels, signs and posters (Bolourian Tehrani, quoted from Kotler, 2004: 9).

Public media or mass media are as impersonal devices sets which cause to transmit the audio or visual message or both of them toward many people and in distant regions. The index of these devices is their relation with the crowd. Therefore, public media are the devices and tools that establish relation between a crowd and another crowd or a person and crowd (Saroukhani, 1996: 471). In other words, public media are said to any kind of device, tools and industry which are applied for selecting, transmitting and receiving the contents like information. Public media are those devices which have been created in new civilizations and the main features of them are the vast power and radius of act. These devices consider the crowd and they can be studied like social institutes. Wiebe considers mass media with regard to their customers. In his opinion, two significant features of mass media are as follows:

1- Their product is available for most of people simply.

2- The costs of accessing to the communicative products are very low that generally financially people achieve them simply.

\subsection{Mental health}

Mental health is a set of factors which have effective role on prevention from creation or progress of the procedure of cognitive and emotional and behavioral disorders dangerousness in human (Shamlu, 2004: 18). World health organization defines mental health in this manner: mental health is inside the general concept of health and health means full ability for playing the mental and physical roles, health doesn't mean lack of disease or retardation.

The mental health association of Canada in a comprehensive view defines mental health in three parts of «the attitudes related to ourselves», «attitudes related to others» and «attitudes related to the life». From the view of this association, mental health means: the ability of compatibility with our and others, views and facing with daily life problems.

Jerarld Kaplan studies mental health in three levels which are : primary prevention, secondary prevention and tertiary prevention.

\subsubsection{Primary prevention}

The purpose of this kind of mental health is to prevent from beginning of a disease or disorder. In other words, this kind of prevention refers to apply the methods and tools which are effective on prevention from advent of disease and strengthen the positive behaviors. The purpose of intervention in the primary prevention stage is to prevent from beginning of disease or disorder, in a manner that reduces the probability of occurring it in a special time section (Shamlu, 2004: 20). It should be added that the above purpose is resulted when we eradicate the causative factors, prevent from contagion and prevalence of disease, reduce the dangerous factors, and increase the resistance and health through creating proper environmental conditions.

\subsubsection{Secondary prevention}

The purposes of acts related to this dimension of mental health program are the early diagnoses and immediate and proper cure of disorder (or disease). In other words, the purpose of second kind of prevention is the early intervention in quick diagnosis and cure of the symptoms of a disease or disorder, with this purpose that the prevalence and expansion of it (in terms of the number of materials) are reduced by shortening its time span.

\subsubsection{Tertiary prevention}

The purposes of this dimension of mental health are the early diagnoses and immediate and proper cure of disorder (or disease) so that the person can return to his familial, social and occupational life in a useful and constructive manner. In fact, the programs of this dimension have dealt with the rehabilitation of persons, prevention from re-return of disorder (or disease) in the person, protection and progress of health created by cure and they complete the previous acts. In other words, the purpose of secondary prevention is to reduce the subsidiary effects which exist in the margin of a main disease or disorder which mostly have chronic nature (ibid reference, page 20). Tertiary prevention with referring to the rehabilitation activities enables the person with long-term mental chronic diseases to do activity with their maximum physical-mental and social abilities. In this line, education of occupational and social skills is very useful. 


\subsubsection{The purpose and principles of mental health}

The main purpose of mental health is the prevention which is gained by creation of a proper individual-social environment.

The significant principles of mental health are:

1- The person's respect to his personality and others.

2- Recognition of limitations in himself and other persons

3- Having the limitations in himself and other persons

4- Acqaintance with this issue that the behavior of each person depends on his existence entirety.

5- Identification of needs and motives which cause to create the human's behavior and acts (Shamlu, 2004: 22).

In 1975, World Health Organization (WHO) announced some of the mental health priorities as follows:

A) Medical urgencies like suicide with diagnosis and cure in the society level

B) Severe or chronic psychosis disorders, mental retardation and epilepsy or cure and support in the society level.

C) The problems of groups exposed to danger like vagrants, aged persons, scholars, students and chronic physical patients.

\subsubsection{Media subject and purpose}

According to the newest definitions that pundits and experts of mass media have presented, the media subject and purpose include the following cases:

Transmission of information, opinions, attitudes or emotions from a person or group to another one or others which is mainly accomplished through symbols (Soroush, 2008: 42). Some other theorists know the media as a process kind in which participants and audiences create information and partake to achieve mutual understanding.

\subsubsection{Media functions}

Nowadays, media with their specified and determining functions have found special position, from informing to create entertainments, from educating and proposing the theoretical, practical and fundamental issues to different reports and news all around the world. All these cases have caused the media currently to play role as one of the most effective factors in creation of public order and safety, mutual agreement, correlation, people participation and mental health of society.

Severin and Tankard in explanation of function and malfunction of media have expressed that an act lonely can have both function and malfunction. In the first function of media which includes the control, supervision, provision and transmission of news, the control function can cause several malfunctions too. With regard to this issue that media mostly warn the social dangers to us, excessive emphasis on dangers and threats probably leads the dread in the society (Severin and Tankard, 2002: 451).

Mass media in the process of social-cultural necessities intervention which is originated from history swiftness in our era, can have constructive or destructive roles. Through the sectors, they can intensify the development imbalance finally. In a concordant media system, cohesion and stability of development and consequently strengthening the national safety are considered. But in disruption of media, threatening the national safety is predictable. In fact, media due to the open connection and relations with social environment are always attempting to create structures.

John Thompson believes if we want to understand the cultural effect of communicative media in the world, we should leave this view that facing with media altogether will lead to leave traditional methods of life and accept the modern methods of life, in facing with media, there is no issue of facing with tradition, communicative media can be used not only for challenging and weakening the traditional values and beliefs but also they can be utilized in order to expand and strengthen the traditions too.

George Gerbner, the innovator of «training theory» believes that we should achieve the perception of distinct aspects of TV effects. These aspects include to be exposed vastly, long-term and vast and non-homogenous public joints which are exposed to the mass production and distribution of media messages (Gerbner, 1986: 21). Gerbner believes that TV and other media have very significant role in the manner of observing the world by people. In today's world, most of people gain their information more from mediator references than their direct experience. Therefore, mediator references are able to form the person's feeling from reality. Especially it is true in relation with violence issue. Much observation of TV trains this feeling that world is a violent place. In this field, Shrum writes: the attitude and opinions of 
intensive- observers of TV are compatible with the orientations demonstrated in TV (Shrum, 1996: 490).

Rubin, Perse and Taylor in their studies found out that the observers of exciting incidents demonstrations feel more anxiety about their safety (Serevin and Tankard, 2002: 394).

The media functions can be included in two groups:

A) Positive function and effects of media

B) Negative function and effects of media

The most important positive and constructive functions of media are:

1- Shrinkage of today's world (our today's world is the global belonging of information).

2- Development of education (media on one hand took the educational content all around the society and on the other hand they have reduced the distance existing among humans) (Saroukhani, 2002: 56).

3- People participation

4- Genesis of national culture

5- Globalization of culture

6- Creation of public order and safety.

Also the most important negative functions of media are:

1- Emergence and expansion of violence and unsafety

2- Domination

3- Transformation of values

4- Transmission of crimes techniques

5- Resistance against moral and cultural values

6- Tendency to the diversity and greed

7- Eradication of mental balance

8- Deculturalization

9- Imposing and promoting the opinions and goods

\subsubsection{TV pathology}

The studies related to the mental-social effect of observing TV are mainly concentrated on the role of violent scenes of TV in the opinions and behaviors of children and this result has been gained that violent scenes of TV have negative and definite consequence on the behavior and beliefs of children and babies.

Puntam claims that TV presents rude and ugly image of the world around us; consequently it causes to create dread and fear of audiences and it creates a kind of unsafety feeling. TV news include crime, war, annihilation and disaster, therefore it will be logical that observers to think that real world is also arduous and painful (Dehrouyeh, 2009, quoted from Uslaner, 1998: 444).

Mass media (such as publications) all days reflect the news related to the crime, incidents and war in the publications of most of countries such as Iran and the regulators of the incidents pages of public newspapers or magazines attempt to publish the most acute and rude crimes with details that these cases have significant role in the abnormal behavior of the society's people.

Regulators of incidents pages of public newspapers or magazines attempt to publish the most acute and rude crimes with details. Extraordinary and unprecedented incidents always have had news value and due to it, they open their place in the column of newspapers. World publications also attempt to observe the excitement aspects in regulation of the news in head-columns and subject to these conditions, the most extraordinary incidents for publications guarantee more readers. For achieving this purpose, the authors don't exaggerate the incidents.

National institute of mental health (in America) with doing more than 2500 researches about the violence relation with real behavior demonstrated through TV achieved this valid result that these kinds of images in fact encourage the aggression behavior among children and adolescents (Roberston, 1995: 132).

\subsubsection{TV and children}

Child and media due to abundant reasons have mutual, constant and effective relation; namely both children are from the most serious interested and applicant of new media especially TV and also media have severe tendency to invest for production of child and adolescents programs for attraction of new generations (Shrum \& et al, 1998).

Cartoons and fairytale doll programs can be sometimes educative for child and they can train the imagination and creativity power. But in some cases, demonstrating huge ogres and animals, shooting, conflicts and dreadful scenes hurt 
the child and cause him to be affected by phantom and fear. These scenes not only influence on the child's attitude to the life but also cause to create violence in him.

Also the studies about TV effect on children indicate that they interpret the things that see and find out this point that many of them «like violence» aren't real (Hodge and Tripp, 1986). Most of children spend much time for observing the TV. In fact, nowadays children allocate most of their time to observe TV instead of learning in classrooms. A discussion which is proposed isn't only about time, rather the content of TV programs is considered important.

The psychological theories about creating motivation for perpetration of crime also mostly indicate the media effectiveness on this process. For sample, many theories have claimed the images which are presented from crime and violence in media are as one of the «social learning» forms and through its imitative or stimulant effects, the persons with eradicating the internal controls arising from disinhibition and desensitization due to the repetitive observation of crime and deviation images may be promoted to perpetrate crime (Warthella, 1995: 11-309). The researches indicate that being constantly exposed to media violence may stimulate invasive tendencies, eradicate sensitiveness to the violent acts and cause the violent acts.

The studies have indicated that children up to 15 years old see tens of thousand violent scenes and thousand scenes of death and murder in cartoon or film on TV and their minds remain influenced by these images for hours (Biddulph, 2007: 116). Potential damages of TV are emerged when children or low-experienced adults inspire from TV characters and consider them as their model. In such conditions, there is this possibility that they hurt each other or behave with each other improperly. Some negative effects and consequences of media on children are as follows:

weakening the mental and emotional relation of child with parents and other family members, attractiveness of media programs (especially visual) has caused the severe interest of child to them and this issue reduces the amount of relation and intimacy of his verbal relations with family members. Children to the extent that allocate time and interest for media communication are deprived from humane and familial relations and consequently they lose the advantages of face to face and oral educations (Esmaieli, 2010). But some of TV programs can teach the method of tolerating others, establishing the proper relation with others, tolerating the ethnic and racial groups to the children.

\subsubsection{Internet and its consequences}

Numerous studies have been accomplished in the field of effects and consequences of internet and satellite.

Subramaniam (2001) indicates that spending much time for using of internet doesn't have negative effect on cognitive skills, rather E-mail may help the interpersonal relations and protection of social relations (quoted from Zanjanizadeh and Javadi, Mohammad, 2005). According to the research results of Kraft, Robert, more use of internet was accompanied with the consequence of familial relations reduction, also it has been reported in the persons who have used of internet more, solitude has been increased (Sleven, 2001: 152). Internet users with dependency on internet have less opportunity for considering the family and this issue may cause to lessen the importance of family by the side of internet user and consequently it reduces the family values (Vindan and et al, 1997: 370). Of course, it is necessary to be said that the important condition for emergence of effects and consequences is the amount of dependency and addiction to some of communicative media. In other words, a channel that people in order to satisfy needs, realize the tendencies and gain the important information feel dependency to it has more ability for creating the effects than a channel that has no difference with another channel and the information that provides is without importance.

\subsubsection{Multui-media crimes}

Literally, multi-media is to «combine the voice, image, animation and film» and in the computer world, multi-media is a sub-group of super-media that combines multi-media and super-textual elements with each other and correlates the information cases with each other.

Multi-media crimes which depend on the crimes of third generation of computer basically can be realized in the cyber space. Therefore, the prohibited behavior of perpetrators of multi-media crimes is different with the behavior of traditional perpetrators (Boroumand, 2004: 60). Multi-media crime includes any kind of legal or moral prohibited activities in relation with abusing of communications and media technology that mainly unknown perpetrators socially do them in unknown space. Criminal behavior in relation with abusing of communication technology includes the crimes against sexual entirety and authority (sexual pornography), crimes against public order or forging and changing the texts, news and information inside internet network and computer data (ibid reference, page 60).

The features of media crime are:

1- media crime violates or eradicates some legal benefits. 
2- The attention center of multi-media crime is the behavioral indecency.

3- Multi-media crime belongs to the publications crimes.

4- The victims of multi-media crime are unlimited and unspecified.

5- Media crime has trans-natural and trans-territorial property.

\subsubsection{Family and pathology of media}

The danger of mass media devices is in this form that some of them take the crimes inside the families. Demonstration of violent acts, exciting scenes, vampires, bare and unveiled photos of women, aggressive and irascible scenes provides the reasons of cruelty, brutality and wickedness of persons unconsciously.

Mass media devices cause the distances to be disappeared, as they clear the wall between humans to high extents. Therefore the family and its functions haven't been also effectless from media interactions and consequences. Familial life isn't merely included in presence in the house, housekeeping or doing some gregarious activities. Familial life is realized really when it is accompanied with exchanging the opinions, feelings, discussion and conversation. Most of people accuse TV that eradicates conversation. Definitely, at the time of observing TV programs, conversation occurs less between the family members, but this conversation isn't eradicated entirely (Kasno, 2005: 152). The main danger is in this form that entering the mass media devices especially TV into the house is accompanied with reduction of discussion and conversation between the family members and consequently lack of reduction of contradiction between the generations. If TV programs are the only conversation subject between children and parents, the danger will be in this form that power exits from house and it is concentrated on the centers out of it and the parents are only the interpreters for expressing these centers. Generally, TV transforms the normal hours of life and creates new habits in spending the time (Wand, 1968) but it doesn't unsteady and destruct the house and family foundation.

\subsubsection{Pornography of children and women}

Unpermitted computer pornography can be mentioned as one of the consequences of new generation media (computer).

The literal definition of pornography is any kind of writing, film, images and issues related to the sexual affairs which are without literal, artistic, political and scientific value and criminal acts in pornography are in this form that a person sells or distributes the audio-visual tools or devices that contain this kind of profligate images and photos or demonstrates such devices or encourages or tempts children and adolescents to participate in this demonstration or pornography (Boroumand, 2004: 59). This kind of criminal acts (pornography) has entered into the mass media with development and progress of technology and internet and they are incomparable in their kind in terms of vastness in the field of distribution. For example, POB boxes, E-mail addresses and internet sites exist in the internet that advertise, distribute and supply the «porno» images.

Another kind of these crimes is the news harassment in the work place, in this form that criminals with manipulating the computer connected to the internet force the victims to observe the sleaze images (pornography) or annoy them with distribution of sexual pornography subjects. The victims of crime subject in sexual pornography are mostly girl and boy children and adults or women that their age range begins from 7 years old.

Pornography criminals divert the children through chat rooms and E-mail and abuse of them sexually in pornography form and distribute their images on sleaze sites.

The issue of abusing of children and pornography which is classified in the crimes against content and media is from very important issues in cyber-crimes that more severe and serious behaviors should be done in prevention and opposition with them.

\subsubsection{Internet as the pervasive media}

Mass media such as internet due to the abundant power, their coverage expanse and diverse functions have deep and undeniable effect on moral individual-social domains. Social sciences scientists call these media in the row of factors related to the socialization and formation of the society's people and believe that mass media can strengthen or weaken the social norms.

The dimensions of internet pathology can be introduced as follows:

1- Depression and social seclusion

Kraut and et al (1998) in a two-year research about internet users concluded that incremental use of internet is accompanied with reduction of familial relation and participation in social-local assemblies. In addition, the participants in 
this research had been affected by social seclusion and depression.

2- Pornography and sexual stimulation

One of the negative consequences of internet is to propagate the prostitution, moral promiscuity and sexual stimulation. Mark Laaser believes currently internet due to have three features has been converted to one of the most important sources of propagation of pornography. These three features are:

1- Easy accessibility to it;

2- The ability of public in payment of its cost

3- Anonemity of its users

Laaser with referring to the negative consequences of internet pornography on mental health says: there is this possibility that children to indicate sexual behaviors from themselves by seeing sleaze issues and images. Also internet pornography can lead to emergence unreasonable sexual behaviors or sometimes sexual addiction. Bullen and Hareh (2000) in a research entitled «internet, its consequences on health and behavior» have called five factors as the damages that threaten the internet users. These factors are:

1- Uncensored nature of internet and disability of persons in precise assessment of information that they face with it.

2- Negative consequences of seeing pornography, sexual and immoral content.

3- The consequences of sexual stimulation; in this cyber space, there is this probability that the persons to be influenced from data and images unconsciously.

4- Potential dangers arising from provision of online personal visits with different persons.

5- The consequences of facing with annoying and threatening the bases or sources.

Addiction to the internet is one of the harmful psychological damages that disrupts the action of normal person and mental health of him in different aspects. Some of the consequences of addiction to the internet are:

1- Severe transformations in life style (in order to spend much time in the network)

2- General reduction of physical activities

3- Disregard to the individual health

4- Remoteness from important activities of life

5- Shortage of sleep or change of sleep patterns

6- Reduction of association and consequently losing the friends and relatives

7- Neglect of family

8- Disregard to the occupational and personal responsibilities

\section{References}

Sleven, James (2001), internet and society, Gligouri, Abbas, Tehran: librarian publication.

Inglehart, Ronald (1994), cultural transformation in the industrial advanced society, Veter, Maryam, Tehran: Kavir publication.

Bastani, Boroumand (2004), computer and internet crimes, Tehran: Behnami publication.

Bolourian Tehrani, Mohammad (2004), media, Tehran: the public relations agencies

Biddulph, Steve (2007), the mystery of happy children, Farahani, Monazzah, Tehran: publication of Peyke Bahar.

Khanbeyki, Hadi (1997), mass media and national safety, (in the articles set of development and public safety conference), Tehran: safety and police deputy of the ministry of interior.

Robertson, Yawn (1995), a prelude on society, Behravan, Hossein, Mashhad: publication of Astan Qods Razavi.

Zanjanizadeh, Homa and Javadi, Alimohammad (2005), studying the effect of internet on family values among the students of region 3 in Mashhad, journal of Iran's society, sixth volume, №.2.

Dehrouyeh, Mohammad (2009). The effect of media on the safety feeling in Tehran city with emphasis on police activities, journal of studies related to prevent from crime, $4^{\text {th }}$ year, No.12.

Saroukhani, Bagher (1996), a prelude on social sciences encyclopedia, Tehran, Keyhan.

Saroukhani, Bagher (2002), the role of mass media devices in prevention from occurrence of crime, Tehran: safety and police deputy of the ministry of interior.

Soroush (1999), the communications revolution in the threshold of 21th century, 20 th year, No.936, Tehran: publications of Islamic Republic of Iran Broadcasting (IRIB).

Severin; Werner, Joseph and Tankard, James W. (2002), communications theories, Dehghan, Alireza, Tehran: Tehran University Publication.

Shamlu, Saeed (2004), mental health, Tehran: Roshd publication.

Shojaie, Mohammadsadegh (2008), psychology and pathology of internet, specialized journal of psychology (interaction with religion) Qom, educational and investigative institute of Imam Khomeini (peace be upon him)

Farjiha, Mohammad, (2006), media reflection of crime, scientific-investigative journal of social welfare, sixth year, No.22. 
Azdanlou, Hamid (2005), acquaintance with significant concepts of sociology, Tehran: Ney publication.

Kasno, Jean (2002), sociology of mass media devices, Saroukhani, Bagher and Mohseni, Manouchehr, Tehran: the publication of information

Lerni, Manouchehr (2008). Criticizing and analyzing the social issues of Iran: the publication of Behineh Faragir.

Mehdizadeh, Sharareh (2005), TV, audience and new attitude, journal of Iran's sociology, sixth volume, No.4.

Newman, Phillip and Newman, Barbara, No.4 (1999), the effects of TV on the growth of children, Bayangard, Esmaiel, journal of Tarbiat, No.10, monthly periodical of ministry of education.

Vartled, Allen and et al (2001), child and violence in America's TV, (in the book of children and violence in mass media), Shafti, Mehdi, Tehran: publication of the center of researches, studies and assessment of Islamic Republic of Iran Broadcasting (IRIB).

Vindal, Seven and et al (1997), application of communications theories, Dehghan, Alireza, Tehran, the center of studies and researches of media.

Hamarberg, Thomas, (2001), children and harmful effects of media on them (in the book of children and violence in mass media), Shafti, Mehdi, Tehran: publication of the center of studies, researches and assessment of Islamic Republic of Iran Broadcasting (IRIB).

Delmas Marti, Miri (2002). Large systems of social politics (first volume), Hosseini Najafi Abrand Abadi, Ali, Tehran: Mizan publication.

Shrum, Y. Durkin, K (1998). TV in children's life, Haghighat Kashani, Tehran: the center of researches, studies and assessment of programs of organization of Islamic Republic of Iran Broadcasting (IRIB).

Esmaieli, Mohsen (2010), child's rights in relation with media, investigative family journal, sixth year, No.21.

Gerbner, G(1986) Perspective on media effects, Hill Sdale, New Jersey, Erlbayum.

edinssonH, (2008-family and televisionT).

Hodge,R.W. Tripp,D.(1986) Children and Television: A Semiotic Approach.Standford:Standford University Publications.

McLuhan,M(1967) The Medium is Massage, Harmond Sworth: penguin.

Sherizen, (1978) Social Creation of Crime News, C.Winick: (Ed) Deviance and Nass Media, Newbury Park, Calif. Sage.

Shrum, Y.J.(1996) Psychological process underlying cultivation effects, Human communication research,vol.32, June.

Uslaner, E. M. (1998) "Social Capital , Television and the Mean Worried: Trust, Optimism and Civil Participation" Political Psychology, Vol: 19. No.3.

Wand , B (1968) Television seeing and family choice differences, in public opinion Quarterly.

Warthella, E(1995) Media and problem Behaviors in Young People. M.Rutter and D.Smith, (eds) Psychological Disorders in Young People, London: Wiley.

www. find articles.com

www.galenet.Grale.group.com 